\title{
Association of depression with sexual function in women with history of recurrent pregnancy Loss: descriptive- correlational study in Tehran, Iran
}

Seyed Ali Azin', Fahimeh Golbabaei², J. Catja Warmelink ${ }^{3,4,5}$, Sadaf Eghtedari', Shima Haghani ${ }^{2}$ and Fahimeh Ranjbar ${ }^{2 *}$ (D)

\begin{abstract}
Purpose: The present study aimed to investigate the relationship between depression and sexual function in women with recurrent pregnancy loss.

Methods: In a cross-sectional correlational study, 130 consecutive patients with history of recurrent pregnancy loss were included who referred to Avicenna Fertility Center in Tehran, Iran during November 2018-February 2019. The outcomes were sexual dysfunction (Assessed with the Female Sexual Function Index) and depression (Evaluated with the Beck's Depression Inventory). The study data were analyzed by using Mann-Whitney and Kruskal-Wallis tests.

Results: The study findings revealed that $40.8 \%$ of the participants suffered from some degrees of depression. The data analysis revealed that depression had a significant inverse correlation with sexual function and its domains $(r=$ $\left.-0.392, p<0.001, R^{2}=0.15\right)$. The spouse' education level and economic status demonstrated a significant relationship with women's sexual function ( $p=0.01, p=0.033$ ). A significant relationship was also detected between women's depression and economic status $(p=0.028)$.

Conclusions: The study findings showed that women with RPL who had severe depression indicated lower score of sexual function. Since psychological and sexual problems are not reported to health care providers due to giving priority to fertility issues or considering such issues as taboos, the assessment of sexual and mental health needs to be part of the consultation in women with history of RPL, whether the patient seeks help for depression and sexual dysfunction or not.
\end{abstract}

Keywords: Depression, Recurrent pregnancy loss, Recurrent miscarriage

\footnotetext{
* Correspondence: ranjbar.f@iums.ac.ir

${ }^{2}$ Nursing Care Research Centre, School of Nursing and Midwifery, Iran University of Medical Sciences, Rashid Yasemi St., Valiasr Ave, Tehran, Iran

Full list of author information is available at the end of the article
}

(c) The Author(s). 2020 Open Access This article is licensed under a Creative Commons Attribution 4.0 International License, which permits use, sharing, adaptation, distribution and reproduction in any medium or format, as long as you give appropriate credit to the original author(s) and the source, provide a link to the Creative Commons licence, and indicate if changes were made. The images or other third party material in this article are included in the article's Creative Commons licence, unless indicated otherwise in a credit line to the material. If material is not included in the article's Creative Commons licence and your intended use is not permitted by statutory regulation or exceeds the permitted use, you will need to obtain permission directly from the copyright holder. To view a copy of this licence, visit http://creativecommons.org/licenses/by/4.0/. The Creative Commons Public Domain Dedication waiver (http://creativecommons.org/publicdomain/zero/1.0/) applies to the data made available in this article, unless otherwise stated in a credit line to the data. 


\section{Introduction}

The experience of pregnancy loss may alter women's physical, psychological and mental health [1]. Pregnancy loss is associated with distress and anxiety which can have a significant emotional impact on women and their spouses [2], specifically within women who have experienced recurrent pregnancy loss (RPL) [3]. Depression, emotional stress, anxiety, fear and sleep disorders have been reported within women with RPL history [4-6]. In some cases, the psychological symptoms of anxiety and depression can persist up to one year [7]. In addition, the psychological consequences of previous miscarriage sustain in subsequent pregnancies [8]. Some studies have investigated the psychological consequences of RPL and revealed that depression is prevalent in women with a history of RPL $[6,9,10]$. The depression prevalence has been reported $41.3 \%$ within pregnant women with RPL history in a study carried out in Brazil [9]. A comparative study was also conducted in Iran and revealed that women who have undergone RPL, experience a lower quality of life as well as more depression and anxiety compared to women without a history of miscarriage [1].

It seems sexual dysfunction has a two-way relationship with depression [11]. Depression-related symptoms such as inability to enjoy, fatigue, and reduced self-esteem can impair one's sexual function, and on the other hand, sexual dysfunction can indirectly result in infertility by decreasing the number of sexual intercourses [12, 13]. A study by Fabre and Smith showed that with increasing severity of depression, sexual dysfunction becomes more severe in women [14]. Results of a study conducted in Australia suggests that presence of any risk factors such as anxiety, depression and sexual dysfunction increases the likelihood of one or two other disorders in the future [15]. Depression is also strongly associated with decreased libido, dyspareunia, and orgasmic disorder [16, 17]. Even in the absence of clinical evidence of depression, negative mood can lead to sexual dysfunction $[18,19]$ and positive or negative sexual experience can affect one's mood throughout the day [16].

Some studies have proposed contradictory results regarding sexual function and depression in women with a history of RPL which indicates the need for further research. A study in Portugal revealed that pregnant women with an RPL history reported more sexual dysfunction than the control group and greater severity of depression led to increased sexual dysfunction, as well [20]. In contrast, the results of another study carried out in Portugal indicated that couples' relationships after miscarriage were similar to those before miscarriage and couples had less problems with respect to talking about sexual issues after miscarriage [21].
The prevalence of RPL in Iran is unclear but it seems that women suffering from RPL or infertility face with more psychological problems and lower quality of life compared to fertile women [22, 23] because Middle Eastern societies such as Iran are family oriented, with a high value placed on childbearing [2]. Furthermore, the prevalence of major depressive disorders is $4.1 \%$ in Iran and women are 1.95 times more likely to have major depressive disorder [24]. Iran is also in the early stages of treating sexual problems and facing a large number of patients who have low sexual knowledge [25]. Since talking about sexual matters is seen as a taboo and discussion about sexual issues is avoided, sexual counseling is often not provided to Iranian women $[26,27]$. As sexuality plays an important role in people's life as well as their wellbeing and family relationships, more researches in the field of sexual health is needed in Iranian setting. Few studies have been carried out on sexual function within women with a history of RPL and to the researchers' knowledge, no study has been conducted in Iran with respect to investigating the association between sexual function and depression in women with history of RPL. For this reason, in this study, an attempt was made to explore the association between depression and female sexual function in the context of recurrent pregnancy loss.

\section{Materials and methods}

The present study was a descriptive-correlational study. Participants were recruited through convenient sampling. Participants were 130 married women with a history of RPL, who referred to Avicenna Fertility Center in Tehran, Iran during November 2018-February 2019. This center is a semi-public center operating under the supervision of the Academic Center for Education, Culture, and Research (ACECR) and providing specialized fertility care in Iran.

In the current study, RPL was defined as the spontaneous loss of two or more clinical pregnancies consecutively before 24 weeks of gestation [2]. Married, nonpregnant Iranian women aged of 21-45 who had two or more consecutive pregnancy losses before 24 weeks of gestation with the minimum interval of six months since the last miscarriage were included in the study. Women who had undergone infertility treatment cycles (IO, IUI, IVF, ICSI) in the past three months or had history of diseases affecting the sexual function or depression were not included. Also, women who initiated their infertility treatment cycles were excluded because these women were potentially at higher risk of sexual dysfunction [28-30].

\section{Instruments}

Participants were requested to fill the demographic/reproductive characteristic checklist, Female Sexual 
Function Index (FSFI), and Beck's Depression Inventory (BDI) after an explanation and giving informed consent.

Demographic/reproductive checklist included independent variables such as age, spouse's age, education level, spouse's education level, job status, spouse's occupation, economic situation, duration of marriage, contraception method, history of infertility, type of RPL, and the time of the last miscarriage.

FSFI was used to assess the participants' sexual function in the previous 4 weeks. The FSFI has 19 items which was first introduced by Rosen (2000) to assess six domains of sexual desire (1 and 2), sexual arousal (3-6), vaginal lubrication (7-10), orgasm (11-13), satisfaction (14-16), and pain (17-19) [31]. Likert scale for each subscale ranging from 0 or 1 to 5 was used in which higher scores indicate better sexual function. The total FSFI score (2 to 36 ) was obtained by summing the scores of the six domains. Higher scores indicate a better sexual functioning with a 28 or lower cut off score indicative of impaired sexual function according to a study in Iran [32]. The validity and reliability of the Persian version of the tool was confirmed by Fakhri et al. [33]. The sexual dysfunction's prevalence in participants was reported in another paper in detail (Under review).

The Beck's Depression Inventory consists of 21 questions based on Diagnostic and Statistical Manual of Mental Disorders, 5th Edition (DSM-5) criteria in order to assess emotional, cognitive, motivational and physiological aspects of depression. Using a four-point Likert scale ranging from zero to three points, the maximum score was 63 and the minimum score 0 . A score of less than $10,10-18,19-29$, and 29-63, respectively demonstrate minimal depression, mild depression, moderate depression and severe depression [34]. This questionnaire was translated into Persian by Ghassemzadeh et al., according to which, internal consistency of $87 \%$ and test-retest reliability of $73 \%$ were obtained [35]. This questionnaire has also been used in Iran for women with a history of RPL [23].

\section{Sample size}

G-Power software was used for calculating the sample size at $95 \%$ confidence interval [36] with power of $80 \%$; the minimum sample size of 85 was needed to achieve correlation coefficient of at least 0.3. Accordingly, a total of 130 participants were included in current study.

\section{Data analysis}

Statistical analysis was performed using SPSS software, version 16 and $P<0.05$ was considered statistically significant. Continuous and categorical variables were displayed as means \pm standard deviation (SD) and percentages, respectively. The Kolmogorov-Smirnov test was used to check the normality of quantitative variables and Mann-Whitney and Kruskal-Wallis tests were used to investigate the relationship between FSFI and BDI with demographic variables. The Spearman correlation coefficient was used to investigate the relationship between FSFI and BDI.

\section{Ethical approval}

Ethical approval was achieved from the Ethics Committee of Iran University of Medical Sciences (IR.IUMS.REC 1396.31743). Women were asked to give written informed consent for their participation. Participants were informed that they are free to participate and can withdraw from the study at any time and this would not influence the quality of care received in this center. Questionnaires were completed anonymously observing the essentials of secrecy and confidentiality of patients and only identifiers were used for each questionnaire.

\section{Results}

In total, 130 women who met the inclusion criteria participated in the study. The mean age of the participants and their husbands was $31.53 \pm 5.11$ and $35 / 74 \pm 5 / 13$ years, respectively. In this study, the majority of the participants were housewives (73.1\%), and more than half of them had university education (55.4\%). In addition, $72.3 \%$ of participants had moderate economic status and $50.8 \%$ of them had marriage duration of 5-9 years. A total of $70.8 \%$ of participants had primary RPL, 39.2\% had history of infertility and $50.8 \%$ were using contraception. Also, the time of the last miscarriage was $<12$ months in $50.8 \%$ of participants. Socio-demographic and reproductive characteristics of the participants are presented in detail in Table 1.

The study findings revealed no relationship between sexual function and participants' characteristics, except for economic situation (Med $=29.2, \quad P=0.01$ ) and spouse's education level (Med $=30.0, P=0.033$ ). Sexual function levels in women whose spouses had university education was significantly higher compared to women whose spouses' education level was high school $(P=$ $0.013)$ and diploma $(P=0.018)$. Moreover, sexual function level turned to be significantly higher than moderate within women with desirable economic status (Med $=14.0, p=0.009)$ and this difference was not significant at other levels. It should be noted that no statistically significant relationship was detected between BDI and demographic/reproductive characteristics, except for economic level $(P=0.028)$. The economic status was the only variable that revealed a statistically significant relationship with depression; depression mean score obtained in women with undesirable economic status was significantly higher than that of women with desirable economic status $(P=0.007)$. There was no significant relationship between age of participants and age of their 
Table 1 The Relationship between participants' Characteristics with Female Sexual Function index and Depression

\begin{tabular}{|c|c|c|c|c|c|c|}
\hline \multirow{2}{*}{$\begin{array}{l}\text { Demographic } \\
\text { Characteristics }\end{array}$} & \multirow[t]{2}{*}{ Categories } & \multirow{2}{*}{$\begin{array}{l}\text { Number } \\
\text { (percentage) }\end{array}$} & \multicolumn{2}{|l|}{ FSFI } & \multicolumn{2}{|l|}{ Depression } \\
\hline & & & $\begin{array}{l}\text { Median( } 95 \% \text { confidence } \\
\text { interval) }\end{array}$ & $\begin{array}{l}\text { Test } \\
\text { result }\end{array}$ & $\begin{array}{l}\text { Median }(95 \% \text { confidence } \\
\text { interval) }\end{array}$ & $\begin{array}{l}\text { Test } \\
\text { result }\end{array}$ \\
\hline \multirow[t]{3}{*}{ Education level } & $\begin{array}{l}\text { High school or } \\
\text { lower }\end{array}$ & $17(13.1)$ & $24.7(23.4,29.1)$ & $\begin{array}{l}{ }^{+\dagger} P= \\
0.098\end{array}$ & $17(12,27)$ & $\begin{array}{l}{ }^{+\dagger} P= \\
0.093\end{array}$ \\
\hline & Diploma & $41(32.3)$ & $28.85(26.8,29.7)$ & & $11(6,14)$ & \\
\hline & Higher education & $71(54.6)$ & $27.9(26.9,29.45)$ & & $11(7,13)$ & \\
\hline \multirow[t]{2}{*}{ Job status } & Housewife & $95(73.1)$ & $27.9(26.2,29)$ & ${ }^{\dagger} P=0.669$ & $12(9,14)$ & ${ }^{\dagger} P=0.569$ \\
\hline & Employed & 35 (26.9) & $28.9(26.4,29.8)$ & & $9(5,18)$ & \\
\hline \multirow[t]{3}{*}{$\begin{array}{l}\text { Spouse's education } \\
\text { level }\end{array}$} & $\begin{array}{l}\text { High school or } \\
\text { lower }\end{array}$ & $22(17)$ & $25.7(23.4,29)$ & ${ }^{+\dagger} P=0.01$ & $17(10.5,23)$ & $\begin{array}{l}{ }^{+\dagger} P= \\
0.075\end{array}$ \\
\hline & Diploma & $36(27.7)$ & $26.9(25.5,28.4)$ & & $13(9.5,14)$ & \\
\hline & Higher education & $72(55.4)$ & $29.2(27.9,29.65)$ & & $8.5(5,11.5)$ & \\
\hline \multirow[t]{2}{*}{ Spouse's occupation } & Self-employment & $85(65.4)$ & $28(26.15,29)$ & ${ }^{\dagger} P=0.332$ & $12(9,14)$ & ${ }^{\dagger} P=0.439$ \\
\hline & Government job & 45 (34.6) & $28.6(27.1,29.79)$ & & $11(6,13)$ & \\
\hline \multirow[t]{3}{*}{ Economic situation } & Undesirable & $20(15.4)$ & $29(25.5,29.45)$ & ${ }^{\dagger \dagger} \mathrm{P}=$ & $14(10,22)$ & ${ }^{+\dagger} \mathrm{P}=$ \\
\hline & Moderate & $94(72.3)$ & $27.3(26,28.85)$ & 0.033 & $11.5(9,13.5)$ & 0.028 \\
\hline & Desirable & $16(12.3)$ & $30(27.8,31.1)$ & & $4.5(3,12.5)$ & \\
\hline \multirow{3}{*}{$\begin{array}{l}\text { Duration of marriage } \\
\text { (year) }\end{array}$} & $5>$ & $24(18.5)$ & $27.2(25.3,29.6)$ & ${ }^{\dagger+} P=$ & $13.5(7,18)$ & ${ }^{\dagger+} P=$ \\
\hline & $5-9 y r$ & $66(50.8)$ & $28.45(26.1,29.19)$ & 0.466 & $13(9,14)$ & 0.347 \\
\hline & $10-14 \mathrm{yr}$ & $40(30.8)$ & $28.6(26.7,29.7)$ & & $7(4,12)$ & \\
\hline \multirow[t]{2}{*}{ Contraception } & No & $64(49.2)$ & $28.9(27.4,29.45)$ & ${ }^{\dagger} \mathrm{P}=0.46$ & $11.5(9,14.48)$ & ${ }^{\dagger} P=0.704$ \\
\hline & Yes & $66(50.8)$ & $27.3(25.9,28.95)$ & & $11(7,13.5)$ & \\
\hline \multirow[t]{2}{*}{ History of infertility } & No & $79(60.8)$ & $27.9(26.4,29.15)$ & ${ }^{\dagger} P=0.683$ & $11(7,13)$ & ${ }^{\dagger} P=0.094$ \\
\hline & Yes & $51(39.2)$ & $28.1(26,29.2)$ & & $14(9,17)$ & \\
\hline \multirow[t]{2}{*}{ Type of miscarriage } & Primary & $92(70.8)$ & $27.95(26.2,29)$ & ${ }^{\dagger} P=0.444$ & $12.5(9,15)$ & ${ }^{\dagger} P=0.125$ \\
\hline & Secondary & $38(29.2)$ & $28.7(26.4,29.8)$ & & $7(5,13)$ & \\
\hline \multirow{3}{*}{$\begin{array}{l}\text { Time of Last } \\
\text { miscarriage } \\
\text { (month) }\end{array}$} & $12>$ & $66(50.8)$ & $28.8(27.2,29.2)$ & ${ }^{\dagger \dagger} P=$ & $12(9,14.5)$ & ${ }^{\dagger+} P=$ \\
\hline & $12-24$ & $33(25.4)$ & $28(25.7,29.89)$ & & $9(6,13)$ & \\
\hline & $24 \leq$ & $32(23.8)$ & $27.1(23.4,29.1)$ & & $13(4,18)$ & \\
\hline \multirow[t]{3}{*}{ Age (years( } & $30>$ & $48(36.9)$ & $26.5(25.6,28.1)$ & ${ }^{+\dagger} P=0.18$ & $11(7,16)$ & ${ }^{\dagger+} P=$ \\
\hline & $30-39$ & $75(57.7)$ & $29(27.6,29.6)$ & & $12(8,13)$ & \\
\hline & $40 \leq$ & $7(5.4)$ & $29.7(16.55,31.55)$ & & $9(4,32.5)$ & \\
\hline \multirow[t]{3}{*}{ Spouse's age (years( } & $30>$ & $13(10)$ & $26.6(25.2,29.05)$ & ${ }^{\dagger \dagger} P=$ & $11(8.5,17)$ & ${ }^{\dagger \dagger} P=$ \\
\hline & $30-39$ & $89(68.5)$ & $28.4(26.4,29.1)$ & 0.182 & $12(9,14)$ & 0.315 \\
\hline & $40 \leq$ & $28(21.5)$ & $28.55(24.71,29.75)$ & & $7.5(2,13)$ & \\
\hline
\end{tabular}

†Mann-Whitney Test +†Kruskal-Wallis Test

spouses with BDI $(P=0.686, P=0.12)$. There was no significant relationship between age of participants and age of their spouses with FSFI $(P=0.297, P=0.723)$ (Table 1$)$.

The study findings revealed that in total, the mean score of FSFI and BDI was $26.59 \pm 5.73$ and $12.61 \pm$ 61.17 , respectively. The results showed that $50.0 \%(n=$ $65)$ of the participants had sexual dysfunction. Rate of minimal, mild, moderate and severe depression were $59.2 \%$ (77), $21.5 \%$ (28), $13.1 \%$ (17) and $6.2 \%$ (8), respectively. Depression showed a statistically significant inverse correlation with FSFI and all of its domains; therefore, decreased scores of FSFI and all of its domains resulted in an increase in the BDI scores $(P<0.001, \mathrm{r}=$ $\left.-0.392, R^{2}=0.15\right)$. Given an $\mathrm{r}$ of -0.392 between FSFI and depression $\left(r^{2}=0.15\right), 15 \%$ of the variance in depression may be attributed to differences among them in FSFI (Table 2). The inverse relationship between FSFI and its domains with BDI is outlined in Fig. 1. 
Table 2 Mean and standard deviation of FSFI and BDI, and Spearman rho correlation between dimensions of FSFI and BDI

\begin{tabular}{lll}
\hline FSFI and its domains & Mean \pm S.d & BDI \\
\hline Desire & $2.73 \pm 0.96$ & $\begin{array}{l}r=-0.241 \\
P=0.006\end{array}$ \\
Arousal & $4.15 \pm 1.09$ & $r=-0.36$ \\
& & $P<0.001$ \\
Vaginal lubrication & $5.04 \pm 1.19$ & $r=-0.22$ \\
Orgasms & & $P=0.012$ \\
Satisfaction & $4.78 \pm 1.29$ & $r=-0.296$ \\
& & $P=0.001$ \\
Pain & $5.04 \pm 1.03$ & $r=-0.324$ \\
& & $P<0.001$ \\
FSFI (total) & $4.83 \pm 1.36$ & $r=-0.33$ \\
& & $P<0.001$ \\
BDI & $26.59 \pm 5.73$ & $r=-0.392$ \\
& & $P<0.001$ \\
FSFIFemale & & -
\end{tabular}

FSFI Female sexual function index, BDI Beck Depression Inventory

\section{Discussion}

In Iran, women react the same as other women in the world and the current study confirmed the high prevalence of sexual dysfunction and depression in women with history of RPL. The data analysis also revealed that FSFI and its domains had a statistically significant inverse correlation with $\mathrm{BDI}$.

More than $40 \%$ of participants in the current study had mild to severe depression. Similarly, it has been reported that depression and emotional stress are extremely prevalent among women with $\operatorname{RPL}[5,6]$. The findings of a study conducted in Iran indicated that women with an RPL history has suffered from significant depression compared to the control group [1]. The findings of two studies conducted in Brazil also showed that more that $40 \%$ of women with an RPL history experienced depression [20,37]. It seems that pregnancy loss has a direct relationship with psychological outcomes in at least some women [38] and a significant percentage of women suffering from RPL have reported a tendency for mental health counseling [39]. Therefore, depression screening should be a necessary part of every counseling visit for women with history of RPL. Health care providers should help Iranian women who avoid treatment due to social stigma associated with mental disease.

The findings showed a significant inverse relationship between BDI and FSFI as well as all its domains in women with history of RPL. Similarly, a study by Fabre and Smith showed that with increasing severity of depression, sexual dysfunction becomes more severe in women [14]. It seems that psychological factors play an important role with respect to sexual issues [9], and sexual dysfunction has a two-way relationship with depression. As a matter of fact, depression is associated with a
$50-70 \%$ increase in sexual dysfunction, and sexual dysfunction increases the risk of depression by $130-200 \%$ [40]. Results of a study conducted in Australia suggests that presence of any risk factors such as anxiety, depression and sexual dysfunction increases the likelihood of one or two other disorders in the future [15]. Depression is also strongly associated with decreased libido, dyspareunia, and orgasmic disorder [16, 17]. Even in the absence of clinical evidence of depression, negative mood can lead to sexual dysfunction $[18,19]$ and positive or negative sexual experience can affect one's mood throughout the day [16].

A study carried out in Portugal indicated that women with an RPL history suffered from depression twice as much as the control group and experienced severe sexual dysfunction; that is to say an increase in their depression score led to a decrease in their sexual function score [20]. Furthermore, in another study in Sweden, sexual dysfunction in women after termination of pregnancy was demonstrated to be associated with depression and anxiety [41]. The relationship between depression and sexual dysfunction in infertile women [22] and women suffering from polycystic ovary syndrome [42] has also been reported. It seems that childbearing difficulties and treatment-related stress can lead to problems in couples' relationships as well as sexual dissatisfaction in this group of women [43]. Mental and sexual health have received scant attention in recurrent miscarriage because the health care providers focus only on the couple's fertility. Sexuality has been surrounded by cultural restrictions, prohibitions, taboos, and indirect regulations in Iran [44]. The results of Javadnoori et al.'s study showed that taboo surrounding sexuality resulted in sexual silence, censorship, or emphasis on negative aspects of sexuality [45]. Therefore, since both depression and sexual dysfunction are common taboos in Iran, both issues can affect the quality of life; as a result, the assessment of sexual and mental health needs to be part of the consultation in women with history of RPL, whether the patient seeks help for depression and sexual dysfunction or not.

No relationship was detected between demographic/ reproductive characteristics and sexual function, except for the economic situation and education level of spouse. Similarly, in a study in Iran that explored the relationship of economic and demographic factors with sexual and marital satisfaction in a sample of Iranian women, men's educational level and finance index were correlated with their marital satisfaction. Linear regression showed that finance index had the strongest relationship with the sexual and marital satisfaction [46]. It seems that economic stressors of treatment negatively affect couples' emotional and sexual intimacy. Highly-educated individuals also appear to have more appropriate 

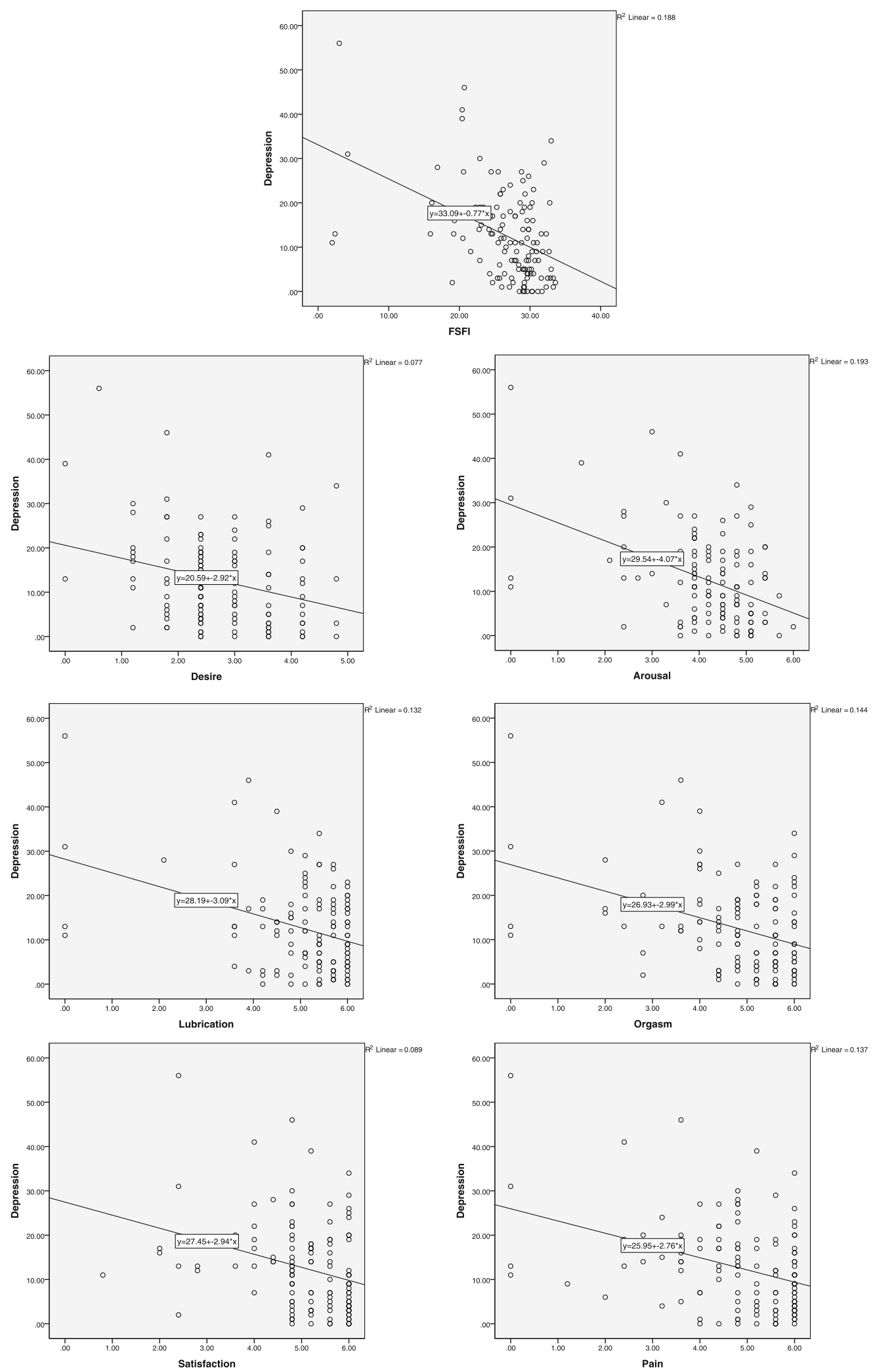

Fig. 1 The scatterplot of FSFI score and its domain with BDI score in women with history of RPL 
occupational status, and fewer chronic stress who enjoy a healthier lifestyle and social support, and have better coping mechanisms and more skills, resulting in higher mental health [47]. Therefore, despite patriarchy in Iran, educated men can be more supportive of their spouses in the face of the socio-cultural pressures of infertility in family. Contrary to our findings, in a study conducted among Iranian infertile women, higher age of women, low education, unwanted marriage, short infertility duration, and low frequency of intercourse were related with sexual dysfunction [48].

The study findings illustrated depression had a statistically significant relationship with economic situation, that is to say women with undesirable economic situation exhibit more depression. Similarly, in a study by $\mathrm{He}$ et al., the low household income was a potential factor affecting depression and anxiety in patients with RPL [6]. Furthermore, it has been proposed that women with lower socio-economic status and those with a history of infertility or prior miscarriages are at greater risk of psychiatric morbidity following miscarriage [49].

In this study, all infertile patients were not excluded and $39.2 \%$ of the participants in the current study had infertility history. Hence, the high cost of infertility treatments in the absence of insurance coverage for infertility treatment in Iran may cause concerns in women with undesirable economic situation. Due to high value of childbearing in Iran, these women may feel depressed to a great extent about being childless than those who have a desirable economic situation. Therefore, women with poor economic status are more susceptible to depression; therefore, it seems necessary to provide more educational programs to teach them how to improve their mental health.

No relationship was found between termination of pregnancy and depression. Similar to our findings, Akker suggested that there is no evidence indicating a link between pregnancy termination and psychological reactions [50]. Keskin et al. also found that women with secondary infertility had decreased sexual function compared to women with primary infertility [51] but there wasn't any relationship between primary or secondary RPL and sexual function in the current study [45].

Our study is the first study conducted in Iran and Middle East region with respect to investigating the association between sexual function and depression in women with history of RPL. One of the strengths of the current study was evaluation of patients from all over Iran who referred to recurrent miscarriage clinic in Tehran. However, the generalizability of the results seems to be difficult due to choosing only one referral miscarriage clinic. Considering limitations, no control group was included, which partially reduces the generalizability of our findings. This study suffers from another limitation which is lack of data about men. Moreover, further interventional research should be done to improve the mental and sexual health of the patients with a history of RPL.

\section{Conclusion}

There is a high prevalence of sexual dysfunction and depression within women with a history of RPL. Our study suggests a significant inverse relationship between depression and sexual function within women with history of RPL. Since psychological and sexual problems are not reported to health care providers or therapists due to giving priority to fertility issues or considering such issues as taboos in Iran, it is considerably essential for health care providers to take into consideration the sexual and psychological matters in RPL patients, who refer to fertility or prenatal clinics, specifically women with low socio-economic status. The findings also confirm the necessity of training health care providers who are expert in the field of reproductive psychology and sexual health in management of patients with fertility problems in Iran.

\section{Acknowledgements \\ The authors would like to thank Mrs. Haleh Maleki and Dr. Soheila Ansaripour for their support; without their help, this project would never have been possible.}

\section{Consent to participate}

Women were asked to give written informed consent for their participation. Participants were informed that they are free to participate and can withdraw from the study at any time and this would not influence the quality of care received in this center. Questionnaires were completed anonymously observing the essentials of secrecy and confidentiality of patients and only identifiers were used for each questionnaire.

\section{Authors'contributions}

SA Azin: Project development, Data analysis, Manuscript editing. F Golbabaei: Project development, Data management, Manuscript writing. JC Warmelink: Data analysis, Manuscript editing. S Eghtedari: Data collection, Data management. Sh Haghani: Data analysis, Manuscript editing. F Ranjbar: Protocol development, Data analysis, Manuscript editing. The author(s) read and approved the final manuscript.

\section{Funding}

This study was funded by a research grant from Iran University of Medical Science (No. 96-03-123-31743).

\section{Availability of data and materials}

The datasets used and analyzed during the present study are available from the corresponding author on reasonable request.

\section{Ethics approval}

Ethical approval was achieved from the Ethics Committee of Iran University of Medical Sciences (IR.IUMS.REC 1396.31743).

\section{Consent for publication}

In the current study, no patients' individual data was used and hence no consent was needed for publication.

Competing interests

The authors declare that they have no competing interests. 


\section{Author details}

'Reproductive Biotechnology Research Center, Avicenna Research Institute, ACECR, Tehran, Iran. ${ }^{2}$ Nursing Care Research Centre, School of Nursing and Midwifery, Iran University of Medical Sciences, Rashid Yasemi St., Valiasr Ave, Tehran, Iran. ${ }^{3}$ Department of Midwifery Science, Amsterdam Public Health Research Institute, VU University Medical Center, Amsterdam, The Netherlands. ${ }^{4}$ Department of General Practice \& Elderly Medicine, University Medical Centre Groningen, University of Groningen, Amsterdam, The Netherlands. ${ }^{5}$ AVAG (Amsterdam/Groningen Midwifery Academy), Amsterdam, The Netherlands.

\section{Received: 18 May 2020 Accepted: 9 November 2020} Published online: 08 December 2020

\section{References}

1. Tavoli Z, Mohammadi M, Tavoli A, Moini A, Effatpanah M, Khedmat L, Montazeri A. Quality of life and psychological distress in women with recurrent miscarriage: a comparative study. Health Qual Life Outcomes. 2018;16(1):150.

2. ESHRE Guideline Group on RPL, Bender Atik R, Christiansen OB, Elson J, Kolte AM, Lewis S, Middeldorp S, Nelen W, Peramo B, Quenby S, Vermeulen N. ESHRE guideline: recurrent pregnancy loss. Human Reproduction Open. 2018;2018(2):hoy004.

3. Mevorach-Zussman N, Bolotin A, Shalev H, Bilenko N, Mazor M, Bashiri A. Anxiety and deterioration of quality of life factors associated with recurrent miscarriage in an observational study; 2012.

4. Gong X, Hao J, Tao F, Zhang J, Wang H, Xu R. Pregnancy loss and anxiety and depression during subsequent pregnancies: data from the C-ABC study. Eur J Obstet Gynecol Reproduct Biol. 2013;166(1):30-6.

5. Kolte A, Olsen LR, Mikkelsen E, Christiansen O, Nielsen HS. Depression and emotional stress is highly prevalent among women with recurrent pregnancy loss. Hum Reprod. 2015;30(4):777-82.

6. He L, Wang T, Xu H, Chen C, Liu Z, Kang X, Zhao A. Prevalence of depression and anxiety in women with recurrent pregnancy loss and the associated risk factors. Arch Gynecol Obstet. 2019;300(4):1061-6.

7. Lok IH, Yip AS-K, Lee DT-S, Sahota D, Chung TK-H. A 1-year longitudinal study of psychological morbidity after miscarriage. Fertil Steril. 2010;93(6): 1966-75.

8. Geller PA, Kerns D, Klier CM. Anxiety following miscarriage and the subsequent pregnancy: a review of the literature and future directions. J Psychosom Res. 2004;56(1):35-45.

9. Carvalho J, Nobre P. Predictors of men's sexual desire: the role of psychological, cognitive-emotional, relational, and medical factors. J Sex Res. 2011:48(2-3):254-62

10. Koert E, Malling GMH, Sylvest R, Krog M, Kolte A, Schmidt L, Nielsen HS. Recurrent pregnancy loss: couples' perspectives on their need for treatment, support and follow up. Hum Reprod. 2019;34(2):291-6.

11. Clayton AH, El Haddad S, Iluonakhamhe J-P, Ponce Martinez C, Schuck AE. Sexual dysfunction associated with major depressive disorder and antidepressant treatment. Expert Opin Drug Saf. 2014;13(10):1361-74.

12. Millheiser LS, Helmer AE, Quintero RB, Westphal LM, Milki AA, Lathi RB. Is infertility a risk factor for female sexual dysfunction? A case-control study. Fertil Steril. 2010;94(6):2022-5.

13. Pakpour $\mathrm{AH}$, Yekaninejad MS, Zeidi IM, Burri A. Prevalence and risk factors of the female sexual dysfunction in a sample of infertile Iranian women. Arch Gynecol Obstet. 2012;286(6):1589-96.

14. Fabre LF, Smith LC. The effect of major depression on sexual function in women. J Sex Med. 2012;9(1):231-9.

15. Forbes MK, Eaton NR, Krueger RF. Sexual quality of life and aging: a prospective study of a nationally representative sample. J Sex Res. 2017; 54(2):137-48.

16. Kalmbach DA, Kingsberg SA, Ciesla JA. How changes in depression and anxiety symptoms correspond to variations in female sexual response in a nonclinical sample of young women: a daily diary study. J Sex Med. 2014; 11(12):2915-27.

17. Leeners B, Hengartner MP, Rössler W, Ajdacic-Gross V, Angst J. The role of psychopathological and personality covariates in orgasmic difficulties: a prospective longitudinal evaluation in a cohort of women from age 30 to 50. J Sex Med. 2014;11(12):2928-37.

18. Hartmann U, Philippsohn S, Heiser K, Rüffer-Hesse C. Low sexual desire in midlife and older women: personality factors, psychosocial development, present sexuality. Menopause. 2004;11(6 Part 2 of 2):726-40.
19. Khandker M, Brady SS, Vitonis AF, MacLehose RF, Stewart EG, Harlow BL. The influence of depression and anxiety on risk of adult onset vulvodynia. J Women's Health. 2011;20(10):1445-51.

20. Francisco MDFR, Mattar R, Bortoletti FF, Nakamura MU. Sexuality and depression among pregnant women with recurrent spontaneous abortion. Revista Brasileira de Ginecologia e Obstetrícia. 2014;36(4):152-6.

21. Serrano F, Lima ML. Recurrent miscarriage: psychological and relational consequences for couples. Psychol Psychother Theory Res Pract. 2006;79(4): 585-94.

22. Shahraki Z, Tanha FD, Ghajarzadeh M. Depression, sexual dysfunction and sexual quality of life in women with infertility. BMC Womens Health. 2018; 18(1):92.

23. Zamani N, Ghasemi M, Jokar E, Khazri Moghadam N. Comparison of depression and life quality of fertile and infertile women and those with frequent abortions. J Babol Univ Med Sci. 2013:15(6):78-83.

24. Sadeghirad B, Haghdoost A-A, Amin-Esmaeili M, Ananloo ES, Ghaeli $P$, Rahimi-Movaghar A, Talebian E, Pourkhandani A, Noorbala AA, Barooti E. Epidemiology of major depressive disorder in Iran: a systematic review and meta-analysis. Int J Prev Med. 2010;1(2):81.

25. Farnam F, Janghorbani M, Raisi F, Merghati-Khoei E. Compare the effectiveness of PLISSIT and sexual health models on Women's sexual problems in Tehran, Iran: a randomized controlled trial. J Sex Med. 2014;11(11):2679-89.

26. Janghorban R, Latifnejad Roudsari R, Taghipour A, Abbasi M, Lottes I. The shadow of silence on the sexual rights of married Iranian women. Biomed Res Int. 2015;2015.

27. Khani S, Moghaddam-Banaem L, Mohamadi E, Vedadhir AA, Hajizadeh E. Women's sexual and reproductive health care needs assessment: an Iranian perspective. East Mediterr Health J. 2018:24(7):637-43.

28. Winkelman WD, Katz PP, Smith JF, Rowen TS, Group IOPP. The sexual impact of infertility among women seeking fertility care. Sexual Med. 2016; 4(3):e190-7.

29. Smith NK, Madeira J, Millard HR. Sexual function and fertility quality of life in women using in vitro fertilization. J Sex Med. 2015;12(4):985-93.

30. Facchin F, Somigliana E, Busnelli A, Catavorello A, Barbara G, Vercellini P. Infertility-related distress and female sexual function during assisted reproduction. Hum Reprod. 2019:34(6):1065-73.

31. Rosen CB, Heiman J, Leiblum S, Meston C, Shabsigh R, Ferguson D, D'Agostino R. R: the female sexual function index (FSFI): a multidimensional self-report instrument for the assessment of female sexual function. J Sex Marital Therap. 2000;26(2):191-208

32. Mohammadi $K$, HEYDARI M, Faghihzadeh S. The female sexual function index (FSFI): validation of the Iranian version; 2008

33. Fakhri A, Pakpour AH, Burri A, Morshedi H, Zeidi IM. The female sexual function index: translation and validation of an Iranian version. J Sex Med. 2012:9(2):514-23.

34. Beck AT, Steer RA, Brown GK. Beck depression inventory-II. San Antonio. 1996:78(2):490-8.

35. Ghassemzadeh $H$, Mojtabai R, Karamghadiri N, Ebrahimkhani $N$. Psychometric properties of a Persian-language version of the Beck depression inventory-second edition: BDI-II-PERSIAN. Depression and anxiety. 2005;21(4):185-92.

36. Cohen J. Statistical power analysis for the behavioral sciences: academic press; 2013.

37. de Carvalho AC, da Silva ME, Matos BM, de Campos Bottino CM, Abrahão AR, Cohrs FM, Bottino SMB. Depression in women with recurrent miscarriages-an exploratory study. Revista Brasileira de Ginecologia e Obstetrícia/RBGO Gynecology and Obstetrics. 2016:38(12):609-14.

38. Reardon DC. The abortion and mental health controversy: a comprehensive literature review of common ground agreements, disagreements, actionable recommendations, and research opportunities. SAGE Open Med. 2018;6: 2050312118807624.

39. Kagami M, Maruyama T, Koizumi T, Miyazaki K, Nishikawa-Uchida S, Oda H, Uchida H, Fujisawa D, Ozawa N, Schmidt L. Psychological adjustment and psychosocial stress among Japanese couples with a history of recurrent pregnancy loss. Hum Reprod. 2012;27(3):787-94

40. Atlantis E, Sullivan T. Bidirectional association between depression and sexual dysfunction: a systematic review and meta-analysis. J Sex Med. 2012; 9(6):1497-507.

41. Bianchi-Demicheli F, Perrin E, Lüdicke F, Bianchi PG, Chatton D, Campana A. Termination of pregnancy and women's sexuality. Gynecol Obstet Investig. 2002;53(1):48-53. 
42. Pastoor H, Timman R, de Klerk C, Bramer WM, Laan ET, Laven JS. Sexual function in women with polycystic ovary syndrome: a systematic review and meta-analysis. Reprod BioMed Online. 2018;37(6):750-60.

43. Muller M, Schilling G, Haidl G. Sexual satisfaction in male infertility. Arch Androl. 1999:42(3):137-43.

44. Shehan CL. The Wiley Blackwell encyclopedia of family studies, 4 Volume Set: Wiley; 2016.

45. Javadnoori M, Roudsari RL, Hasanpour M, Hazavehei SMM, Taghipour A. Female adolescents' experiences and perceptions regarding sexual health education in Iranian schools: a qualitative content analysis. Iran J Nurs Midwifery Res. 2012;17(7):539.

46. Darooneh T, Ozgoli G, SHeikhan Z, Nasiri M. A study on the relationship of economic and demographic factors with sexual and marital satisfaction in a sample of Iranian women, 2015-2016; 2017.

47. Halpern-Manners A, Schnabel L, Hernandez EM, Silberg JL, Eaves LJ. The relationship between education and mental health: new evidence from a discordant twin study. Social Forces. 2016;95(1):107-31.

48. Maroufizadeh S, Riazi H, Lotfollahi H, Omani-Samani R, Amini P. The 6-item female sexual function index (FSFI-6): factor structure, reliability, and demographic correlates among infertile women in Iran. Middle East Fertility Soc J. 2019;24(1):7.

49. Nynas J, Narang P, Kolikonda MK, Lippmann S. Depression and anxiety following early pregnancy loss: recommendations for primary care providers. Primary Care Companion CNS Disord. 2015;17(1):10.4088/PCC. $14 \mathrm{r} 01721$.

50. Van den Akker OB. The psychological and social consequences of miscarriage. Expert Review of Obstetrics \& Gynecology. 2011;6(3):295-304.

51. Keskin U, Coksuer H, Gungor S, Ercan CM, Karasahin KE, Baser I. Differences in prevalence of sexual dysfunction between primary and secondary infertile women. Fertil Steril. 2011;96(5):1213-7.

\section{Publisher's Note}

Springer Nature remains neutral with regard to jurisdictional claims in published maps and institutional affiliations.

Ready to submit your research? Choose BMC and benefit from:

- fast, convenient online submission

- thorough peer review by experienced researchers in your field

- rapid publication on acceptance

- support for research data, including large and complex data types

- gold Open Access which fosters wider collaboration and increased citations

- maximum visibility for your research: over $100 \mathrm{M}$ website views per year

At $\mathrm{BMC}$, research is always in progress.

Learn more biomedcentral.com/submissions 